\title{
EFEITO DO PREBIÓTICO E DO ÁCIDO BUTÍRICO IN OVO SOBRE O DESEMPENHO, DIGESTIBILDADE DOS NUTRIENTES DA RAÇÃO E BIOMETRIA DO TRATO GASTRINTESTINAL DE PINTOS SUBMETIDOS AO JEJUM
}

\author{
Nadja Susana Mogyca Leandro, ${ }^{1,3}$ Adson Santa Cruz de Oliveira, ${ }^{2}$ Marcos Barcelos Café,,${ }^{1,3}$ Elisabeth \\ Gonzales, ${ }^{3}$ José Henrique Stringhini, ${ }^{1,3}$ Fabyola Barros de Carvalho e Maria Auxiliadora Andrade ${ }^{1}$
}

1. Professores doutores da EV/UFG. E-mail: mogyca@vet.ufg.br

2. Pós-graduando em Ciência Animal EV/UFG

3. Bolsista CNPq

4. Pós-doutoranda EV/UFG.

RESUMO

Desenvolveram-se dois experimentos para avaliar o desempenho, a digestibilidade de nutrientes da ração e a biometria de órgãos do trato gastrintestinal de pintos, oriundos de ovos inoculados com prebiótico ou ácido orgânico, submetidos a jejum hídrico e alimentar. Os ovos férteis foram inoculados com uma solução contendo prebiótico (experimento I) ou água (grupo placebo), no saco alantoide aos dezesseis dias de incubação. No experimento II, os ovos embrionados foram inoculados com água (placebo) ou ácido orgânico (butirato de sódio). Depois da eclosão, selecionaram-se duzentos pintos pelo peso, sendo distribuídos de acordo com os tratamentos em baterias. O delineamento foi em blocos casualizados, em esquema fatorial $2 \times 2$ (inóculos x períodos de jejum), totalizando quatro tratamentos e dez repetições. Os períodos de jejum estudados foram de oito (grupo-controle) e 36 horas após a eclosão. O prebiótico inoculado reduziu o ganho de peso $(\mathrm{P}<0,05)$ e não afetou a digestibilidade e a biometria dos órgãos. A inoculação in ovo não prejudicou o peso inicial dos pintos e não houve interação entre o inóculo e o período de jejum. A inoculação com ácido orgânico não afetou o desempenho das aves e a digestibilidade dos nutrientes, mas aumentou a biometria intestinal $(\mathrm{P}<0,05)$. A suplementação de prebiótico ou butirato de sódio não melhorou o desempenho dos pintos até os dez dias de idade, tampouco a digestibilidade dos nutrientes da ração, independentemente se submetidos ou não ao jejum inicial. Porém, o butirato de sódio favoreceu o desenvolvimento intestinal.

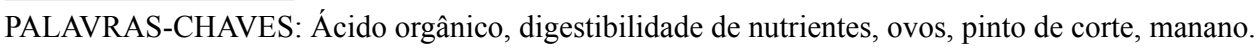

\section{EFFECT OF PREBIOTIC AND BUTYRIC ACID IN EGG ON THE PERFORMANCE, NUTRIENTS DIGESTIBILITY OF THE DIET AND BIOMETRY OF THE GASTOINTESTINAL TRACT OF CHICKS UNDER FASTING}

Two experiments were conducted to evaluate the performance, digestibility of nutrients of the diet and biometry of the gastrointestinal tract of chicks from eggs inoculated with prebiotic or butyric acid, submitted to water and food fasting. The fertile eggs were inoculated with a solution containing prebiotic (experiment I) or water (placebo group), in the allantoic sac on the $16^{\text {th }}$ day of the incubation. In experiment II, the fertile eggs were inoculated with water (placebo group) or organic acid (sodium butyrate). After hatching, 200 chicks were selected and classified by weight and distributed according to the treatments in battery cages. A randomized complete block design in $2 \times 2$ factorial scheme (inoculants $\mathrm{x}$ fasting time) was used, totaling four treatments and 10 replicates. The fasting times evaluated were eight (control group) and 36 hours after hatching. The inoculation of butyric acid did 
not affect the performance of chicks and nutrients digestibility, but the gastrointestinal biometry was increased $(\mathrm{P}<0.05)$. The prebiotc reduced the weight gain $(\mathrm{P}<0.05)$ and affected neither the nutrients digestibility nor the gastrointestinal biometry. The inoculation in the eggs did not harm the initial weight of the chicks as well as there was no interaction between the inoculant and the fasting time. The supplementation with prebiotic or butyric acid neither improved the performance of chicks until ten days of age nor the nutrients digestibility of the diet, irrespective if the chicks were under fasting or not. However, the butyric acid enhanced the gastrointestinal tract development.

KEYWORDS: Broilers, inoculated eggs, manano, nutrients digestibility, organic acid.

\section{INTRODUÇÃO}

O jejum pós-eclosão prejudica o desempenho de pintos de corte até a fase final de criação (NIR \& LEVANON, 1993; PINCHASOV \& NOY, 1993). Do mesmo modo, o jejum afeta o desenvolvimento do trato gastrintestinal (TGI) das aves. GONZALES et al. (2008) observaram que aves alimentadas logo após a eclosão apresentaram maior desenvolvimento do intestino e do pâncreas e concluíram que o período de restrição alimentar pós-eclosão prejudica a maturidade do TGI. GONZALES et al. $(1999,2008)$ relataram que pintos de corte submetidos a 36 horas de jejum após a eclosão apresentaram dificuldades na absorção dos nutrientes do saco vitelino e menores pesos dos órgãos secretores (fígado, pâncreas e intestino), refletindo em prejuízos no desempenho aos 42 dias de idade. Do mesmo modo, ALMEIDA et al. (2006) observaram pior desempenho aos 42 dias de idade para as aves submetidas a jejum de 48 horas. UNI et al. (1998) e MAIORKA et al. (2000) observaram que a restrição alimentar após a eclosão prejudicou o desenvolvimento intestinal de pintos de corte.

Normalmente entre a eclosão e o alojamento, os pintos de corte são submetidos a uma restrição hídrica e alimentar, período esse que pode variar de 24 a 48 horas, resultantes da preparação e descanso dos pintos no incubatório associado ao tempo de transporte até as granjas. Em consequência desse jejum, os pintos podem sofrer uma desidratação e uma perda de peso de até 10\% (BAIÃO \& CANÇADO, 1998). No entanto, a maturidade do TGI e o estabelecimento precoce da microbiota intestinal podem ser estimulados pela suplementação exógena de nutrientes ou aditivos (GUILLOT, 2000; LEANDRO et al., 2010), promovendo maior desempenho dos pintos de corte. Dentre os produtos que podem ser considerados fatores tróficos para induzir a maturidade do TGI estão os probióticos e prebióticos (MAIORKA, 2001) e acidificantes orgânicos (DIBNER \& BUTTIN, 2002; RICKE, 2003).

Os prebióticos são definidos como ingredientes alimentares não hidrolisáveis pelas enzimas endógenas dos animais e que beneficiam o animal, por estimularem seletivamente o crescimento e/ou a atividade de um limitado número de bactérias no intestino, favorecendo a saúde e o desempenho do animal. Carboidratos oligo e polissacarídeos, alguns peptídeos e proteínas e certos lipídeos e fibras são considerados prebióticos (GIBSON \& ROBERFROID, 1995). Entretanto, as substâncias que têm sido mais estudadas como aditivos prebióticos em alimentação animal são os oligossacarídeos, especialmente os frutoligossacarídeos (FOS), glucoligossacarídeos (GOS) e mananooligossacarídeos (MOS).

O MOS não é digestível pelas aves, mas é alimento específico para as bactérias consideradas úteis (ROBERFROID, 1998). Além de funcionar como substrato para as bactérias úteis, estimulando o seu crescimento e/ou ativando o metabolismo, o MOS atua como bloqueador dos sítios de aderência de certas bactérias patogênicas, imobilizando e reduzindo a capacidade desses agentes de se manterem no TGI (COLLINS \& GIBSON, 1999).

Estudos com desempenho de frangos de corte suplementados com prebióticos apresentam resultados contraditórios. Algumas pesquisas mostram melhoras no desempenho com uso do produto (TOLEDO et al., 2003; PELICANO et al., 2004; ALBINO et al., 2006; SILVA et al., 2009). Um estudo refere que não houve efeito significativo sobre o ganho de peso e conversão alimentar (PAZ et al., 2010). Um outro estudo demonstrou efeito positivo do produto sobre o desenvolvimento intestinal de pintos criados em ambientes com alta temperatura (SILVA et al., 2010).

Outro produto pesquisado com o objetivo de favorecer o balanço da microbiota intestinal é o ácido orgânico. Trata-se de uma substância que facilita a co- 
lonização do TGI pelas bactérias úteis, promovendo um amadurecimento mais rápido da mucosa do intestino delgado de pintos (JANSSENS \& NOLLET, 2002). O efeito inibidor da proliferação de enterobactérias no trato digestório, provocado pela utilização do ácido orgânico na ração, deve-se à redução do $\mathrm{pH}$ na parte superior do intestino delgado, promovendo um aumento de disponibilidade de nutrientes e potencializando os ganhos nutricionais das dietas (FREZZA, 2008; FARIA et al., 2009). Os ácidos orgânicos mais usados na avicultura são o fórmico, o acético, o propiônico, o butírico, o lático, o cítrico e o fumárico, apresentando, respectivamente, os seguintes pKa: 3,$75 ; 4,76 ; 4,87$; 4,81; 3,86; 3,09/4,75/5,41; 3,03/4,54.

GARCIA et al. (2000) não encontraram qualquer efeito dos ácidos orgânicos sobre o ganho de peso e conversão alimentar dos frangos até abate (42 dias de idade). No entanto, estudos em que aves foram desafiadas mostraram resultados positivos com o uso de ácidos orgânicos, como a redução das unidades formadoras de colônia de Campylobacter (CHAVEERACH et al., 2002) e do número total de coliformes e de Escherichia coli no duodeno, jejuno e ílio (IZAT et al., 1990) e o favorecimento no desenvolvimento de bactérias aeróbicas na água (CHAVEERACH et al., 2004).

De acordo com PEDROSO et al. (2005), a colonização do trato gastrintestinal pela microbiota natural nas aves se inicia antes mesmo da eclosão. Assim, a inoculação de prebiótico e ácido orgânico via ovo pode favorecer a colonização de bactérias desejáveis, antecipando a maturidade do TGI das aves.

Objetivou-se, com este estudo, avaliar o efeito do prebiótico ou do ácido orgânico inoculado em ovos embrionados e do período de jejum após a eclosão sobre o desenvolvimento do TGI e desempenho de pintos de corte até os dez dias de idade.

\section{MATERIAL E MÉTODOS}

Realizaram-se dois experimentos, sendo estudados no experimento I a inoculação de prebióticos em ovos embrionados e no experimento II o ácido butírico. Em cada experimento foram utilizados trezentos ovos de matrizes da linhagem Cobb-500, com 46 semanas de idade, provenientes do incubatório comercial da região. Transportaram-se os ovos no
15 dia de incubação para a Escola de Veterinária da UFG, sendo distribuídos em quatro incubadoras, com capacidade para 120 ovos cada, para completar o período de incubação.

Instalaram-se as incubadoras em uma única sala, sendo os ovos pesados, uniformizados e distribuídos nas incubadoras. Estas foram reguladas e monitoradas diariamente, para se manter a temperatura e a umidade relativa em $37,5^{\circ} \mathrm{C}$ e $55 \%$, respectivamente, até o final da incubação.

No 16을 dia de incubação, os ovos (experimento I) foram inoculados com $0,30 \mathrm{~mL}$ de água destilada (placebo) ou com o mesmo volume de solução contendo $40 \mathrm{mg}$ do prebiótico comercial $\mathrm{MOS}^{\circledR 1}$. Esse produto era composto por lactose (15\%) e mananooligossacarídio (85\%). A inoculação foi efetuada na cavidade alantoide, utilizando-se uma seringa de 1,0 $\mathrm{mL}$ e uma agulha de $13 \mathrm{~mm}$ estéreis para cada ovo de acordo com a metodologia proposta por LEITÃO et al. (2008).

Após o nascimento e seleção dos pintos de corte pelo peso corporal, duzentas aves (não sexadas) provenientes de ambas inoculações (água x prebiótico) foram alojadas em baterias de gaiolas, equipadas com comedouros e bebedouros tipo linear e bandejas metálicas. Metade dos pintos, inoculados com água ou prebiótico, foram submetidos a um jejum hídrico e alimentar de oito a 36 horas. Estudou-se, assim, a combinação entre o tipo de inóculo (placebo ou MOS) e períodos de jejum após a eclosão (oito ou 36 horas), totalizando quatro tratamentos. $\mathrm{O}$ tratamento com oito horas de jejum foi considerado o grupo-controle, já que este seria o tempo mínimo necessário para um incubatório comercial entregar pintos de um dia para o alojamento.

O mesmo procedimento foi adotado para o experimento II, sendo a diferença apenas no produto inoculado. Realizou-se a inoculação no ovo de 0,30 $\mathrm{mL}$ de água destilada ou o mesmo volume de solução contendo $8,0 \mathrm{mg}$ do butirato de sódio a $98 \% \pm 2 \%$ (Adimix ${ }^{\mathrm{TM}}$ Butyrate-C, Invenutri-AD).

Para o alojamento, empregaram-se 240 pintos da linhagem Cobb 500 (não sexados) de um dia de idade, provenientes dos trezentos ovos inoculados com água ou ácido butírico de acordo com os trata-

1 Mananooligossacarídeo, BIOCAMP 
mentos. Metade dos pintos, inoculados com água ou ácido butírico (Adimix ${ }^{\mathrm{TM}}$ Butyrate-C, Invenutri-AD), foram submetidos ao jejum hídrico e alimentar após a eclosão de 8 e 36 horas. Assim, procedeu-se ao estudo da combinação entre o tipo de inóculo (placebo ou ácido butírico) e períodos de jejum após a eclosão (controle de 8 horas de jejum ou 36 horas de jejum), semelhante ao experimento I.

A ração utilizada durante todo o período experimental era composta por ingredientes vegetais (à base de milho e farelo de soja), isentas de agentes anticoccidianos e de antibióticos como promotores de crescimento. A ração era farelada e formulada para conter $21 \%$ de proteína bruta e de $3.000 \mathrm{kcal} \mathrm{EM} / \mathrm{kg}$ de ração.

Para a avaliação do desempenho foram considerados: consumo de ração, ganho de peso, conversão alimentar (corrigida para mortalidade) e mortalidade.

Efetuou-se o ensaio de digestibilidade pelo método de colheita total das excretas, durante o período de seis a dez dias de idade dos frangos. A ingestão de ração foi controlada e diariamente faziam-se duas coletas de toda a excreta produzida (pela manhã e à tarde), que era acondicionada em sacos plásticos e conservada em freezer, para análises posteriores. As análises bromatológicas da matéria seca, proteína bruta, extrato etéreo e do nitrogênio foram feitas de acordo com a metodologia proposta por SILVA \&
QUEIROZ (2002). Calcularam-se os coeficientes de digestibilidade da matéria seca (CDMS), da proteína bruta (CDPB), do extrato etéreo (CDEE) e o balanço de nitrogênio.

As análises biométricas do proventrículo, da moela, do fígado e do intestino foram realizadas com pintos de um e de dez dias de idade, utilizando-se dez aves por tratamento, sacrificadas por deslocamento cervical e pesadas individualmente para a coleta dos órgãos.

Os dados de percentagem de mortalidade foram transformados em Arc seno e as análises estatísticas para todas as variáveis realizadas pelo procedimento GLM do $\operatorname{SAS}^{\circledR}(2001)$.

\section{RESULTADOS E DISCUSSÃO}

Não houve interação entre os fatores inoculação de prebiótico e período de jejum após a eclosão (Tabela 1). Assim, a suplementação de prebiótico na fase embrionária não melhorou o desempenho de pintos submetidos ao jejum de 36 horas em relação aos embriões oriundos de ovos não inoculados com prebiótico (grupo placebo). O ganho de peso e o consumo de ração foram inferiores $(p<0,05)$ para pintos que receberam o prebiótico via ovo e para aqueles submetidos ao período de 36 horas de jejum pós-eclosão.

TABELA 1. Desempenho de pintos de corte na fase pré-inicial oriundos de ovos inoculados com placebo ou prebiótico aos dezesseis dias de incubação e submetidos a 8 ou 36 horas de jejum após a eclosão

\begin{tabular}{|c|c|c|c|c|c|}
\hline Tratamentos & Peso inicial (g) & Ganho de peso (g) & $\begin{array}{c}\text { Consumo de ração } \\
(\mathrm{g})\end{array}$ & Conversão alimentar & $\begin{array}{c}\text { Mortalidade } \\
\text { (transformada) }\end{array}$ \\
\hline \multicolumn{6}{|l|}{ Inóculo } \\
\hline Placebo & 49 & $213 a$ & $260 \mathrm{a}$ & 1,217 & 0,258 \\
\hline Prebiótico & 48 & $196 b$ & $240 \mathrm{~b}$ & 1,219 & 0,255 \\
\hline \multicolumn{6}{|l|}{ Jejum } \\
\hline Controle (8h) & 48 & $211 \mathrm{a}$ & $259 \mathrm{a}$ & 1,223 & 0,258 \\
\hline 36 horas & 48 & $199 b$ & $241 b$ & 1,212 & 0,255 \\
\hline $\mathrm{CV}(\%)$ & 2,5 & 4,18 & 8,71 & 7,63 & 36,29 \\
\hline
\end{tabular}

Médias seguidas de letras distintas, na mesma coluna, diferem pelo teste $\mathrm{F}(0,05)$.

*mortalidade transformada $=$ Arc seno $((\% \text { Mort. } / 100)+0,05)^{0,5} . \mathrm{ns}=$ não significativo $(\mathrm{p}>0,05)$.

Os menores valores para ganho de peso, observados em pintos provenientes de ovos inoculados com prebiótico, discordam dos resultados obtidos por IJI \&
TIVEY (1998), os quais observaram que frangos suplementados com prebiótico apresentaram maior consumo de ração e ganho de peso em relação ao grupo-controle 
(sem aditivos). Assim como TOLEDO et al. (2003) e ALBINO et al. (2006), que encontraram resultados positivos para desempenho em frangos suplementados com prebiótico, porém todos esses autores estudaram o uso do probiótico suplementado na ração.

As boas condições higiênicas do experimento proporcionaram baixo desafio sanitário das instalações. De acordo com a literatura, aditivos como os prebióticos são mais efetivos em condições de maior desafio. SPRING et al. (2000) explicam que o MOS atua bloqueando os sítios de ligação de bactérias patogênicas na mucosa intestinal, diminuindo, assim, as injúrias ao TGI e consequentemente reduzindo o turnover celular da mucosa, o que proporciona melhor utilização dos ingredientes da dieta e desempenho zootécnico. Esses autores, ao testarem MOS como promotor de crescimento, observaram que o prebiótico promoveu o desenvolvimento da microbiota intestinal, melhorando o desempenho das aves. SANTIN et al. (2003) observaram que aves desafiadas e alimentadas com o prebiótico apresentaram maior ganho de peso e melhor conversão alimentar que as aves do grupo-controle.

Com relação ao período de jejum, observou-se que pintos submetidos a 36 horas de restrição alimen- tar e hídrica, após a eclosão, apresentaram pior ganho de peso (Tabela 1) quando comparados com controle (oito horas de jejum). Corroborando este estudo, PINCHASOV \& NOY (1993) e BAIÃO \& CANÇADO (1998) afirmaram que pintos submetidos a um período de 24 e 48 horas de jejum após a eclosão podem sofrer desidratação e perda de peso de até $10 \%$. Do mesmo modo, NIR \& LEVANON (1993) observaram um atraso no crescimento de pintos de corte, provocado pelo jejum de 24 e 48 horas, equivalente a um ou dois dias de ganho peso, respectivamente, e GONZALES et al. (2008) observaram efeitos negativos sobre o peso vivo de frangos de corte quando os pintos foram submetidos ao período de 24 horas de jejum, após o nascimento.

Os resultados de digestibilidade da matéria seca, da proteína bruta, do extrato etéreo e o balanço de nitrogênio são apresentados na Tabela 2. As análises estatísticas demonstram que os resultados de coeficientes de digestibilidade foram semelhantes entre $o$ grupo-controle e o suplementado com prebiótico. No entanto, o prebiótico prejudicou o balanço de nitrogênio $(\mathrm{p}<0,05)$.

TABELA 2. Coeficiente de digestibilidade dos nutrientes e o balanço de nitrogênio na ração de pintos provenientes de ovos inoculados com placebo ou prebiótico e a 36 horas de jejum após a eclosão

\begin{tabular}{|c|c|c|c|c|}
\hline \multirow[t]{2}{*}{ Tratamento } & \multicolumn{4}{|c|}{ Coeficiente de digestibilidade } \\
\hline & Matéria seca (\%) & Proteína bruta (\%) & Extrato etéreo (\%) & Balanço de nitrogênio $(\mathrm{g})$ \\
\hline \multicolumn{5}{|l|}{ Inóculo } \\
\hline Placebo & 74,00 & 68,60 & 95,85 & $1,72 \mathrm{a}$ \\
\hline Prebiótico & 73,79 & 68,26 & 95,60 & $1,32 b$ \\
\hline \multicolumn{5}{|c|}{ Período de jejum } \\
\hline Controle (8h) & 74,15 & 68,74 & 95,90 & 1,66 \\
\hline 36 horas & 73,64 & 68,13 & 95,60 & 1,37 \\
\hline $\mathrm{CV}(\%)$ & 1,82 & 2,60 & 1,68 & 27,50 \\
\hline
\end{tabular}

Médias seguidas de letras distintas, na mesma coluna, diferem pelo teste $\mathrm{F}(0,05)$.

$n s=$ não significativo $(\mathrm{p}>0,05)$.

Resultados obtidos por LODDI et al. (2000) também mostraram que não houve diferença na digestibilidade da PB e MS da ração entre pintos que recebem ou não prebiótico na dieta. Entretanto, FERES et al. (2002), verificando os efeitos do prebiótico mananooligossacarídio, concluíram que o aditivo melhorou os coeficientes de digestibilidade da matéria seca e da proteína digestível, além de melhorar a energia metabolizável aparente e energia metabolizável aparente corrigida para o balanço de nitrogênio, pelo método de coleta ileal, quando este foi comparado com a ração-controle. 
Os resultados da biometria do TGI mostraram que não houve diferenças $(\mathrm{p}>0,05)$ entre os tratamentos no primeiro (dados não apresentados) ou no décimo dia de vida (Tabela 3). O prebiótico não influenciou o desenvolvimento do TGI dos pintos durante o pe- ríodo final da fase embrionária, assim como na fase pré-inicial de crescimento. O jejum de 36 horas após a eclosão interferiu negativamente somente sobre o peso absoluto da moela $(\mathrm{p}<0,05)$.

TABELA 3. Peso absoluto e relativo dos componentes do TGI de pintos, oriundos de ovos inoculados com placebo ou prebiótico e submetidos a 36 horas de jejum após a eclosão, aos dez dias de idade

\begin{tabular}{|c|c|c|c|c|c|c|c|}
\hline \multirow{3}{*}{ Variável } & \multirow{3}{*}{ Inóculo } & \multicolumn{4}{|c|}{ Período de jejum } & & \\
\hline & & \multicolumn{2}{|c|}{ Controle (8h) } & \multicolumn{2}{|c|}{$36 \mathrm{~h}$} & \multicolumn{2}{|c|}{ Média } \\
\hline & & (g) & $\%^{1}$ & (g) & $\%^{1}$ & (g) & $\%^{2}$ \\
\hline \multirow{3}{*}{ Proventrículo, $\mathrm{g}$} & Placebo & 2,2 & 0,8 & 2,0 & 0,8 & 2,1 & 0,8 \\
\hline & Prebiótico & 2,2 & 0,9 & 2,0 & 0,8 & 2,1 & 0,8 \\
\hline & Média & 2,2 & 0,8 & 2,0 & 0,8 & & \\
\hline \multirow{3}{*}{ Moela, g } & Placebo & $13,0 \mathrm{a}$ & 5,0 & $11,6 b$ & 4,6 & 12,3 & 4,8 \\
\hline & Prebiótico & $12,1 \mathrm{a}$ & 4,8 & $10,9 b$ & 4,5 & 11,5 & 4,6 \\
\hline & Média & 12,6 & 4,9 & 11,3 & 4,6 & & \\
\hline \multirow{3}{*}{ Fígado, $g$} & Placebo & 9,6 & 3,6 & 8,8 & 3,5 & 9,2 & 3,6 \\
\hline & Prebiótico & 9,5 & 3,7 & 9,1 & 3,7 & 9,3 & 3,7 \\
\hline & Média & 9,5 & 3,7 & 9,0 & 3,6 & & \\
\hline \multirow{3}{*}{ Peso do intestino, $\mathrm{g}$} & Placebo & 16,2 & 6,2 & 16,4 & 6,6 & 16,3 & 6,4 \\
\hline & Prebiótico & 16,4 & 6,4 & 16,2 & 6,7 & 16,3 & 6,5 \\
\hline & Média & 16,3 & 6,3 & 16,3 & 6,6 & & \\
\hline \multirow{3}{*}{ Comp. do intestino/cm } & Placebo & 94,2 & & 92,0 & & 93,1 & \\
\hline & Prebiótico & 91,4 & & 90,4 & & 90,9 & \\
\hline & Média & 92,8 & & 91,2 & & & \\
\hline \multirow{3}{*}{$\mathrm{g} / \mathrm{cm}$ do intestino } & Placebo & 0,17 & & 0,17 & & 0,17 & \\
\hline & Prebiótico & 0,17 & & 0,17 & & 0,17 & \\
\hline & Média & 0,17 & & 0,17 & & & \\
\hline
\end{tabular}

${ }^{1}$ Em relação ao peso vivo da ave; ${ }^{2}$ transformado em arco seno antes da análise estatística.

As médias seguidas de letras a e b na mesma linha diferem pelo teste $\mathrm{F}(\mathrm{P}<0,05)$.

Esses dados indicam que os prejuízos observados para ganho de peso em pintos submetidos ao jejum não resultaram de alterações do desenvolvimento do TGI dos pintos, que não foram influenciados pelo período de jejum. Desse modo, o menor ganho de peso observado em pintos submetidos ao jejum de 36 horas deve estar relacionado com o baixo consumo de ração pelos pintos. Dados contrários foram observados por GONZALES et al. (2008), os quais relataram que pintos de corte submetidos a 36 horas de jejum apresentaram menor peso dos órgãos secretores (fígado, pâncreas e intestino). MAIORKA et al.
(2000, 2001) observaram que o comprimento e o peso do intestino de pintos de corte receberam influência do período de 24 horas de restrição alimentar após a eclosão.

Os resultados de desempenho de pintos de corte na fase pré-inicial oriundos de ovos embrionados inoculados com placebo ou butirato de sódio (experimento II) estão apresentados na Tabela 4. Pode-se observar que não houve interação entre os tratamentos inóculos e jejum para todas as variáveis estudadas. A suplementação in ovo de butirato não influenciou o desempenho, resultado esse que não está de acordo 
com os dados de RUNHO et al. (1997), GARCIA et al. (2000) e SILVA et al. (2009), os quais mostraram que o ácido orgânico administrado na ração melhorou a conversão alimentar de frangos de corte na fase inicial. No entanto, VALE et al. (2004) verificaram piora no ganho de peso ma fase inicial de criação de frango de corte.

TABELA 4. Desempenho de pintos na fase pré-inicial, provenientes de ovos inoculados com ácido butírico ou placebo e submetidos a 8 ou 36 horas de jejum após a eclosão

\begin{tabular}{lccccc}
\hline & \multicolumn{5}{c}{ Variáveis estudadas } \\
\cline { 2 - 6 } Tratamentos & $\begin{array}{c}\text { Peso inicial } \\
(\mathrm{g})\end{array}$ & $\begin{array}{c}\text { Ganho de peso } \\
(\mathrm{g})\end{array}$ & $\begin{array}{c}\text { Consumo de ração } \\
(\mathrm{g})\end{array}$ & $\begin{array}{c}\text { CA } \\
(\mathrm{kg} / \mathrm{kg})\end{array}$ & $\begin{array}{c}\text { Mortalidade } \\
\text { (transf.*) }\end{array}$ \\
\hline Inóculo & & & & 1,280 & 0,251 \\
\hline Placebo & 49,72 & 190 & 243 & 1,270 & 0,238 \\
Ácido orgânico & 49,14 & 187 & 236 & $1,220 \mathrm{~b}$ & 0,238 \\
\hline Período de jejum & & & 241 & $1,340 \mathrm{a}$ & 0,238 \\
\hline Controle $(8 \mathrm{~h})$ & 49,41 & $199 \mathrm{a}$ & 238 & 7,63 & 36,00 \\
36 horas & 49,46 & $179 \mathrm{~b}$ & & & \\
CV(\%) & 2,2 & 4,22 & & & \\
\hline
\end{tabular}

Médias seguidas de letras diversas na mesma coluna diferem pelo teste $\mathrm{F}(\mathrm{P}<0.05)$.

*M=Mortalidade transformada: Arc seno $((\% \text { Mort. } / 100)+0,05)^{0,5}$. ns $=$ não significativo $(\mathrm{p}>0,05)$.

Da mesma forma que no experimento I, as condições ambientais possivelmente proporcionaram baixo desafio sanitário para os pintos que foram criados em baterias com baixa densidade de aves. Os ácidos orgânicos são substâncias com potencial para modificar o $\mathrm{pH}$ do TGI das aves, favorecendo a microbiota natural, e quando as aves são submetidas às condições de desafio o fornecimento de ácidos orgânicos melhora o desempenho destas (DIBNER \& BUTTIN, 2002; RICKE, 2003).

O jejum prejudicou o ganho de peso e a conversão alimentar $(p<0,05)$. No entanto, o balanço de nitrogênio (Tabela 5) foi influenciado positivamente $(p<0,05)$ pelo jejum após a eclosão, o que pode estar relacionado a um ganho compensatório na utilização de nitrogênio dietético, não acompanhado de aumento na excreção de nitrogênio endógeno, embora esse resultado não tenha sido observado no Experimento I. Corroborando esses resultados, ROSTAGNO et al. (2004) explicaram que a digestão de determinadas moléculas é potencializada quando se encontram em menor concentração na dieta.

TABELA 5. Coeficiente de digestibilidade e balanço de nitrogênio da ração de pintos provenientes de ovos inoculados com placebo ou ácido butírico e submetidos a 8 ou 36 horas de jejum após a eclosão

\begin{tabular}{lcccc}
\hline \multirow{2}{*}{ Tratamentos } & \multicolumn{4}{c}{ Coeficiente de digestibilidade (\%) } \\
\cline { 2 - 5 } & Matéria seca (\%) & Proteína bruta (\%) & Extrato etéreo (\%) & B Nitrogênio (g) \\
\hline Inóculo & & & 95,80 & 25,11 \\
Placebo & 77,13 & 66,94 & 94,81 & 24,30 \\
Ácido orgânico & 74,22 & 63,23 & & \\
Período de jejum & & & 94,87 & $22,67 \mathrm{~b}$ \\
Controle & 73,32 & 62,48 & 95,74 & $26,75 \mathrm{a}$ \\
36 horas & 78,03 & 67,70 & 1,94 & 24,15 \\
CV(\%) & 10,06 & 19,64 & & \\
\hline
\end{tabular}

Médias seguidas de letras diversas na coluna diferem estatisticamente entre si pelo teste $F(p<0,05)$. $n s=$ não significativo $(p>0,05) . n s=$ não significativo $(p>0,05)$. 
O fato de o ácido orgânico ser um produto que age como um agente antimicrobiano (JANSSENS \& NOLLET, 2002) pode explicar os dados de menor peso para os órgãos do TGI combinados com o maior comprimento do intestino, encontrado, neste experimento, para pintos oriundos de ovos inoculados com ácido butírico (Tabela 6). Esses resultados sugerem que houve uma diminuição da espessura da mucosa intestinal decorrente de uma proteção do TGI, conferida pelo acidificante. Segundo FURLAN et al.
(2001), a menor relação entre peso e comprimento do intestino indica uma menor espessura da mucosa intestinal, o que se deve, provavelmente, à maior proteção ou às menores injúrias pelas quais os pintos foram submetidos, pois, caso contrário, a mucosa tornar-se-ia mais espessa, resultando em maior peso e aumento na demanda por nutrientes. No entanto, os dados de digestibilidade dos nutrientes e os de conversão alimentar não diferiram entre pintos que receberam o ácido butírico e o controle.

TABELA 6. Peso absoluto e relativo dos componentes do TGI e comprimento do intestino de pintos de corte, aos dez dias de idade, originados de ovos inoculados com placebo ou ácido orgânico e submetidos a 8 ou 36 horas de jejum

\begin{tabular}{|c|c|c|c|c|c|c|c|}
\hline \multirow{3}{*}{ Variáveis } & \multirow{3}{*}{ Inóculo } & \multicolumn{6}{|c|}{ Período de jejum } \\
\hline & & \multicolumn{2}{|c|}{ Controle } & \multicolumn{2}{|c|}{$36 \mathrm{~h}$} & \multicolumn{2}{|c|}{ Médias } \\
\hline & & (g) & $\%^{1}$ & (g) & $\%^{1}$ & (g) & $\%^{2}$ \\
\hline \multirow[t]{3}{*}{ Proventrículo, } & Placebo & $2,3 \mathrm{~A}$ & $1,0 \mathrm{~A}$ & 2,0 & 0,9 & 2,2 & 1,0 \\
\hline & Ácido butírico & $2,0 \mathrm{~B}$ & $0,8 \mathrm{~B}$ & 2,1 & 0,9 & 2,0 & 0,9 \\
\hline & Média & 2,2 & 0,9 & 2,0 & 0,9 & & \\
\hline \multirow[t]{3}{*}{ Moela, g } & Placebo & 12,2 & 5,6 & 11,0 & 5,0 & 11,6 & $5,3 \mathrm{a}$ \\
\hline & Ácido butírico & 10,8 & 4,7 & 10,4 & 4,7 & 10,6 & $4,7 \mathrm{~b}$ \\
\hline & Média & 11,5 & 5,1 & 10,7 & 4,8 & & \\
\hline \multirow[t]{3}{*}{ Fígado, $\mathrm{g}$} & Placebo & 7,9 & 3,6 & 8,4 & 3,8 & 8,2 & 3,7 \\
\hline & Ácido butírico & 7,8 & 3,4 & 8,3 & 3,7 & 8,1 & 3,5 \\
\hline & Média & 7,9 & 3,5 & 8,4 & 3,8 & & \\
\hline \multirow[t]{3}{*}{ Intestino, $\mathrm{g}$} & Placebo & 17,5 & 7,9 & 17,1 & 7,8 & 17,3 & $7,9 \mathrm{a}$ \\
\hline & Ácido butírico & 17,2 & 7,5 & 16,6 & 7,4 & 16,9 & $7,5 \mathrm{~b}$ \\
\hline & Média & 17,4 & 7,7 & 16,8 & 7,6 & & \\
\hline \multirow[t]{3}{*}{ Intestino, $\mathrm{cm}$} & Placebo & 87,7 & - & 79,9 & - & $83,8 \mathrm{a}$ & - \\
\hline & Ácido butírico & 88,1 & - & 80,2 & - & $84,2 \mathrm{~b}$ & - \\
\hline & Média & 87,9 & - & 80,0 & - & & - \\
\hline
\end{tabular}

${ }^{1}$ Em relação ao peso vivo da ave antes do abate.

${ }^{2}$ Transformado em arco seno antes da análise estatística.

$\mathrm{A}, \mathrm{B}$, na coluna, mostra o efeito da inoculação dentro de jejum, pelo teste $\mathrm{F}(\mathrm{P}<0,05)$.

a,b, na coluna, mostra o efeito da inoculação, independente do jejum, segundo o teste $\mathrm{F}(\mathrm{P}<0,05)$.

Os resultados de desempenho com a aplicação do prebiótico ou ácido orgânico, via ovo, em pintos submetidos ao jejum não diferiram dos resultados dos pintos não suplementados com os aditivos que sofreram semelhante jejum. Assim, a inoculação desses aditivos antes da eclosão não acelerou o processo de estabelecimento da população bacteriana estável e benéfica no TGI das aves e por falta de desafio experimental não se pode concluir que esses aditivos excluíram ou limitaram a colonização de patógenos.

\section{CONCLUSÕES}

A suplementação de prebióticos MOS ${ }^{\circledR}$ ou de butirato de sódio (Adimix ${ }^{\mathrm{TM}}$ Butyrate-C, Invenutri- 
$\mathrm{AD}^{\circledR}$ ) em embriões de frangos de corte não melhorou o desempenho dos pintos ou a digestibilidade dos nutrientes da ração, na fase pré-inicial. Esses aditivos inoculados em ovos embrionados não aceleraram a maturidade do TGI de pintos submetidos ou não ao jejum alimentar por 36 horas após a eclosão.

\section{REFERÊNCIAS}

ALBINO, L. F. T.; FERES, F. A.; DIONIZIO, M. A., ROSTAGNO, H. S.; VARGAS JÚNIOR, J. G.; CARVALHO, D. C. O.; GOMES, P. C.; COSTA, C. H. R. Uso de prebióticos à base de mananoligossacarídeo em rações para frangos de corte. Revista Brasileira de Zootecnia, v. 35, p. 742-749, 2006.

ALMEIDA, J. C.; DAHLKE, F.; MAIORKA, A.; MACARI, M.; FURLAN, R. L. Efeito do jejum no intervalo entre o nascimento e o alojamento sobre o desempenho de frangos de corte provenientes de matrizes de diferentes idades. Archives of Veterinary Science, v. 11, p. 50-54, 2006.

BAIÃO, N. C.; CANÇADO, S. V. Efeito do intervalo entre o nascimento e o alojamento de pintos sobre o desempenho dos frangos. Arquivo Brasileiro de Medicina Veterinária e Zootecnia, v. 50, p. 191-194, 1998.

CHAVEERACH, P.; KEUZENKAMP, D. A.; LIPMAN, L. J. A.; VAN KNAPEN, F. Effect of organic acids in drinking water for young broilers on campylobacter infection, volatile fatty acid production, gut microflora and histological cell changes. Poultry Science, v. 83, p. 330-334, 2004.

CHAVEERACH, P.; KEUZENKAMP, D. A.; URLINGS, H. A. P.; LIPMAN, L. J. A.; KNAPEN, F. In vitro study on the effect of organic acids on Campylobacter jejuni/coli populations in mixtures of water and feed. Poultry Science, v. 81, p. 621-628, 2002.

COLLINS, M. D.; GIBSON, G. R. Probiotics, prebiotics, and synbiotics: approaches for modulating the microbial ecology of the gut. American Journal of Clinical Nutrition, v. 69, p. 1052S-1057S, 1999.

DIBNER, J. J.; BUTTIN, P. Use of organic acids as a model to study the impact of gut microflora on nutrition and metabolism. Journal of Applied Poultry Research, v. 11, p. 453-463, 2002.

FARIA, D. E.; HENRIQUE, A. P. F.; FRANZOLIN NETO, R.; MEDEIROS, A. A.; JUNQUEIRA, O. M.; FARIA FILHO, D. E. Alternativas ao uso de antibióticos como promotores de crescimento para frangos de corte: 2 . Ácidos orgânicos e probióticos. Ciência Animal Brasileira, v. 10, n. 1, p. 29-39, 2009.
FERES, F. A.; ALBINO, L. F. T.; ROSTAGNO, H. S.; CARVALHO, D. C. O.; OLIVEIRA, J. E.; VARGAS JUNIOR, J. G.; SASAKI, A. H. Digestibilidade e energia metabolizável do prebiótico à base de mananoligossacarídeo para frangos de corte. In: REUNIÃO ANUAL DA SOCIEDADE BRASILEIRA DE ZOOTECNIA, 39., 2002, Recife, PE, Anais... Recife, PE, 2002. Disponível em: <http://www.sbz.org.br/_media/reuniaoanual/sbz2002.rar>

FREZZA, A. L. C. Probióticos na ração de frangos de corte e sua influência no $\mathbf{p H}$ do ingluvio e na microbiota intestinal. Dissertação, 2008, 37 f. Mestrado (Ciências Veterinárias - Produção Animal) - Faculdade de Medicina Veterinária, Universidade Federal de Uberlândia. Disponível em: $<$ http://www. bdtd.ufu.br//tde busca/arquivo.php? codArquivo=2019>. Acesso em: 30 setembro 2010.

FURLAN, R. L.; CARVALHO, N. C.; MALHEIROS, E. B.; MACARI, M . Efeito da restrição alimentar inicial e da temperatura ambiente sobre o desenvolvimento de vísceras e ganho compensatório em frangos de corte. Arquivo Brasileiro de Medicina Veterinária e Zootecnia, v. 53, p. 492-498, 2001.

GARCIA, R. G.; ARIKI, J.; MORAES, V. M. B.; KRONKA, S. N. N; BORGES, S. A.; MURATA, L. S.; CAMPOS, V. A. Ação isolada ou combinada de ácidos orgânicos e promotor de crescimento em rações de frangos de corte. Revista Brasileira de Ciência Avícola. 2000. Disponível em: <http://www.scielo.br/ scielo.php?script=sci_arttext\&pid=S1516-35X2000000200004> Acesso em: 20 out. 2010.

GIBSON, G. R; ROBERFROID, M. B. Dietary modulation of the human colonic microflora: introducing the concept of prebiotics. Journal of Nutrition, v. 12, p. 1401-1412, 1995.

GONZALES, E.; STRINGHINI, J. H.; DAHLKE, F.; CUNHA, W. C. P.; XAVIER, S. A. G. Productive consequences of fasting neonatal chicks of different genetic constitutions for growing. Revista Brasileira Ciência Avícola, v. 10, n. 4, p. 253-256, 2008.

GUILLOT, J. F. The pros and cons of probiotics: make probiotics work for poultry. World Poultry, v. 16, p. 18-21, 2000.

IJI, P. A.; TIVEY, D. R. Natural and synthetic oligossaccharides in broiler chicken diets. World's Poultry Science Journal, v. 54, p. $129-143,1998$.

IZAT, A. L.; TIDWELL, N. M.; THOMAS, R. A.; M. A.; ADAMS, M. H.; COLBERG, M.; WALDROUP, P. W. Effects of buffered propionic acid in diets on the performance of broiler chickens and on microflora of the intestine and carcass. Poultry Science, v. 69, p. $818-826,1990$.

JANSSENS, G.; NOLLET, L. Sodium butyrate in animal nutrition. In: SIMPÓSIO SOBRE INGREDIENTES NA ALIMENTAÇÃO 
ANIMAL, 2., 2002, Uberlândia, MG. Anais... Uberlândia: CBNA, 2002. p. 239-250.

LEITÃO, R. A.; LEANDRO, N. S. M.; CAFÉ, M. B.; STRINGHINI, J. H.; PEDROSO, A. A.; CHAVES, L. S. Inoculação de glicose em ovos embrionados de frangos de corte: parâmetros de incubação e desempenho inicial. Ciência Animal Brasileira, v. 9, p. 847$855,2008$.

LODDI, M. M.; GONZALES, E.; TAKITA, T. S.; MENDES, A. A.; ROÇA, R. O. Uso de probiótico e antibiótico sobre o desempenho, o rendimento e a qualidade de carcaça de frangos de corte Revista Brasileira de Zootecnia, v. 29, p. 1124-1131, 2000.

MAIORKA, A.; SANTIN, E.; FISCHER DA SILVA, A. V.; BRUNO, L. D. G.; BOLELI, I. C.; MACARI, M. Desenvolvimento do trato gastrintestinal de embriões oriundos de matrizes pesadas de 30 e 60 semanas de idade. Revista Brasileira de Ciência Avícola, 2000. Disponível em: <http://www.scielo.br/scielo. php?pid=S1516-635X2000000200003\&script $=$ sci_arttext $>$ Acesso em: 20 out. 2010.

MAIORKA, A.; SANTIN, E.; SUGETA, S. M.; ALMEIDA, J. G.; MACARI, M. Utilização de prebióticos, probióticos ou simbióticos em dietas para frangos. Revista Brasileira de Ciência Avícola, 2001. Disponível em: <http://www.scielo.br/scielo. php?script $=$ sci_arttext\&pid $=$ S1516-35X2001000100008 $>$ Acesso em: 20 out. 2010.

NIR, I.; LEVANON, M. Research note: effect of postthach holding time performance and residual yolk and liver composition. Poultry Science, v. 72, p. 1994-1997, 1993.

PAZ, A. S.; ABREU, R. D.; COSTA, M. C. M. M.; JAEGER, S. M. P. L.; ROCHA, A. P.; FERREIRA, B. P.; SANTANA, R. S.; CAMPOS, B. M. Aditivos promotores de crescimento na alimentação de frangos de corte. Revista Brasileira de Saúde e Produção Animal, v. 11, p. 395-402, 2010.

PEDROSO, A. A.; MENTEN, J. F. M.; LAMBAIS, M. R. The structure of bactéria community in the intestines of newly hatched chicks. Journal of Applied Poultry Research, v. 14, p. 232-237, 2005.

PELICANO, E. R. L.; SOUZA, P. A.; SOUZA, H. B. A.; LEONEL, F. R.; ZEOLA, N. M. B. L.; BOIAGO, M. M. Productive traits of broiler chickens fed diets containing different growth promoters. Revista Brasileira de Ciência Avícola, v. 6, p. 177-182, 2004.

PINCHASOV, Y.; NOY, Y. Comparison of post-hatch holding time and subsequent early performance of broiler chicks and turkey poultry. Poultry Science, v. 34, p. 111-120, 1993.
RICKE, S. C. Perspectives on the use of organic acids and short chain fatty acids as antimicrobials. Poultry Science, v. 82, p. 632-639, 2003.

ROBERFROID, M. B. Prebiotics and synbiotics: concepts and nutritional properties. British Journal of Nutrition, v. 80, p. S197-S202, 1998.

ROSTAGNO, H. S.; DIONIZIO, M. A.; ALBINO, L. F. T. Perspectivas da nutrição de frangos de corte. In: REUNIÃO ANUAL DA SOCIEDADE BRASILEIRA DE ZOOTECNIA, 41., 2004, Campo Grande, Anais... Campo Grande: SBZ, MS, 2004. Disponível em: <http://www.sbz.org.br/reuniaoanual/ anais/?idiom=pt $>$. Acesso em: 25 set 2010.

RUNHO, R. C.; SAKOMURA, N. K.; KUANA, S.; BANZATTO, D.; JUNQUEIRA, O. M.; STRINGHINI, J. H. Uso de ácido orgânico (ácido fumárico) nas rações de frangos de corte. Revista Brasileira de Zootecnia, v. 26, p. 1183-1191, 1997.

SANTIN, E.; PAULILLO, A. C.; KRABBE, E. L.; ALESSI, A. C.; POLVEIRO, W. J. C.; MAIORKA, A. Low level of aflatoxin in broiler at experimental conditions: use of cell wall yeast as adsorbent of aflatoxin. Archives of Veterinary Science, v. 8, p. 51-55, 2003.

SAS. User's Guide, version 6. 4. ed. North Caroline: SAS Institute INC, 2001. 1686 p.

SILVA, D. J.; QUEIROZ, A. C. Análise de alimentos: métodos químicos e biológicos. 2. ed. Viçosa: UFV, 2002. 235 p.

SILVA, V. K.; SILVA, J. D. T.; GRAVENA, R. A.; MARQUES, R. H.; HADA, F. H.; MORAES, V. M. B. Yeast extract and prebiotic in pre-initial phase diet for broiler chickens raised under different temperatures. Revista Brasileira de Zootecnia, v. 39, p. $165-174,2010$.

SPRING, P.; WENK, C.; DAWSON, K. A.; NEWMAN, K. E. The effects of dietary mannanoligosaccharides on cecal parameters and the concentrations of enteric bacteria in the ceca of Salmonella-challenged broler chicks. Poultry Science, v. 79, p. 205-211, 2000.

TOLEDO, M. S.; ROSTAGNO, H. S.; ALBINO, L.F. T.; CARVALHO, D. C. O.; OLIVEIRA, J. E.; DIONIZIO, M. A. Efeito de prebióticos e milhos de diferente qualidade nutricional sobre o desempenho de frangos de corte na fase inicial. In: REUNIÃO ANUAL DA SOCIEDADE BRASILEIRA DE ZOOTECNIA, 40., 2002, Recife Anais... Recife: SBZ, PE, 2003. Disponível em: $<$ http://www.sbz.org.br/reuniaoanual/anais/?idiom=pt $>$. Acesso em: 25 set. 2010. 
UNI, Z.; GANOT, S.; SKLAN, D. Posthach development of mucosal function in the broiler small intestine. Poultry Science, v. 77, p. 75-82, 1998.
VALE, M. M.; MENTEN, J. F. M.; MORAIS, S. C. D.; BRAINER, M. M. A. Mixture of formic and propionic acid as additives in broiler. Scientia Agricola, v. 61, p. 371-375, 2004.

Protocolado em: 19 nov. 2008. Aceito em: 17 jun. 2010. 